\title{
Stimulus effectiveness in avoidance behavior in fish'
}

DAVID W. JACOBS, DEPARTMENT OF ANIMAL BEHAVIOR, AMERICAN MUSEUM OF NATURAL HISTORY, New York, and DEPARTMENT OF PSYCHOLOGY, FAIRLEIGH DICKINSON UNIVERSITY, Teaneck, N.Y., AND ARTHUR N. POPPER, DEPARTMENT OF BIOLOGY, THE CITY COLLEGE OF THE CITY UNIVERSITY OF NEW YORK

Two groups of pinfish (Lagodon rhomboides), were trained to make avoidance responses in a shuttlebox. One group was trained to a visual CS, the other group to an auditory CS. Animals trained to the auditory stimulus did not learn the task as readily as animals trained to the visual stimulus, as indexed by the number of animals reaching criterion in a 31 day period and by the median acquisition rate. The finding is the opposite of what had previously been found in the rat. This species difference may be related to the capacities of the animals to make discriminations of signals presented in different modalities.

Many factors affect the capacity of an animal to respond rapidly to stimuli indicating the presence of danger. The sensitivity of the animal to different kinds of signals is probably one of these factors. For a visually oriented animal, light cues should be much more effective than are sound cues in eliciting an avoidance response, while the opposite would be true for an acoustically oriented animal. Evidence that there is a difference in the effectiveness of different stimuli comes from experiments reported by D'Amato, Keller, \& DiCara (1964) and Biederman (1967) who have shown that in the laboratory rat, sound stimulation significantly increases rate of acquisition in an avoidance task as compared with light stimulation. In this paper we report a similar experiment which investigated the effect of light vs sound signals in avoidance conditioning in a marine fish.

Procedure. The Ss were 21 pinfish (Lagodon rhomboides) collected in the bay adjoining the Mote Marine Laboratory, Sarasota, Florida. The animals used averaged 60 to $70 \mathrm{~mm}$ in standard length, which would make them approximately nine to 10 months old at the time of testing (Caldwell, 1957). The fish were kept in 9.5 liter acquaria with continuously flowing seawater. The water in the home and test tanks averaged about $24 \mathrm{deg} \mathrm{C}$.

The animals were randomly divided into two groups. The first was trained utilizing light as the signal. The source was an incandescent lamp adjusted to deliver $19 \mathrm{ft}-\mathrm{c}$ of light to the wells of the test tank. The second group was trained using $500 \mathrm{~Hz}$ sine wave sound stimulus produced by an audio-oscillator. The sound pressure level was $+5 \mathrm{~dB}$ (re $1 \mu \mathrm{b}$ ) measured in the wells of the tank. These stimulus intensities were chosen because prior experiments had shown that the animal would respond to the signals when they were at these values.

The procedure used in the study followed that developed by Behrend \& Bitterman (1962) and used automated control mechanisms previously described (Jacobs \& Tavolga, 1967; Tavolga, 1966). The animals were tested in a rectangular tank $(29 \mathrm{~cm}$ long, $9 \mathrm{~cm}$ wide and $10 \mathrm{~cm}$ deep) divided into two wells by a hurdle which the animal had to cross as his response to the signal. The water level over the hurdle was high enough to permit the fish to cross the barrier but low enough to inhibit random crossings of the barrier. The test tank was placed in a darkened, sound reducing chamber to eliminate ambient stimulation. Responses were monitored by a photocell mounted at the hurdle of the tank. For a given trial, the stimulus (either a light or a sound) came on for 10 sec. If the animal crossed the hurdle in that time, it avoided the shock and was given a $60 \mathrm{sec}$ intertrial interval before the signal came on again. If he failed to cross in the $10 \mathrm{sec}$ interval, the signal was maintained and a pulsed shock, $10 \mathrm{VAC}$, was administered through electrodes placed at the ends of the tank. The shock was delivered at the rate of 1 pulse/sec, for $0.1 \mathrm{sec}$ duration. If the fish still failed to respond, the shock stayed on for another $10 \mathrm{sec}$, at which time both stimulus and shock were turned off and the intertrial interval begun again. The time from onset of the signal to
Table 1

Frequencies of Successful and Unsuccessful Animals in Light and Sound Conditions

\begin{tabular}{l|c|c|}
\multicolumn{1}{c}{ Successful } & \multicolumn{2}{c|}{ Unsuccessful } \\
\cline { 2 - 3 } Light & 10 & 2 \\
\cline { 2 - 3 } & 4 & 5 \\
& 4 & 21
\end{tabular}

crossing and the number of intertrial crossings were automatically recorded. Animals were given 25 trials per day.

Results and Discussion. Significant differences appeared in effects of light vs sound stimulation on acquisition of the avoidance response. Table 1 shows the number of animals trained in the light and sound conditions that reached criterion within a 31 day training period. As the row analysis indicates, of the 12 animals trained in light, 10 successfully completed training. Of the nine trained in sound, only four successfully completed training. A Fisher Exact Probability test was performed on these frequencies to determine if the differences in proportions of success as a function of modality of training were significant. A p value of .07 was obtained. In addition, training was faster to a light than to a sound stimulus. Table 2 shows the number of days of training to reach the first day of criterion. The median number of days of training for four sound animals was 21 days. For the 10 light animals the median number of training days was 4.5. Only one light animal, No. 109, had a training day score higher than the lowest sound animal. The Mann-Whitney $U$ test showed the differences were significant at the .01 level.

These results indicate that in the pinfish, as in the rat, significant differences in avoidance behavior occur as a function of which modality is stimulated. But the effects of light vs sound are opposite in the two species. In the rat acquisition was faster to sound than to light whereas the reverse was true in the pinfish.

Such behavior is consistent with the demands placed upon these animals by their respective ecological niches. The young pinfish is most active during daylight in shallow water where visual signals are critical (Caldwell, 1957). For any animals that are primarily sound-oriented, as the nocturnal rat is likely to be, the effectiveness of light vs sound stimuli would be reversed. A similar effect could be predicted in fish which are sound producers and therefore sound oriented. While no evidence for this is available at this time, Tavolga \& Wodinsky (1963) report that learning of the avoidance response to a sound stimulus in sound-producers such as

Table 2

No. of Training Days to Criterion for Indjividual Fish

\begin{tabular}{ccc} 
& Fish & \\
No. & Acquisition \\
\hline SigHT & 101 & 5 \\
& 103 & 3 \\
& 105 & 2 \\
& 106 & 2 \\
& 107 & 9 \\
& 108 & 1 \\
& 109 & 26 \\
& 110 & 4 \\
& 111 & 18 \\
& 112 & 7 \\
\hline SOUND & 4 & 21 \\
& 31 & 20 \\
& 32 & 21 \\
& 33 & 26 \\
\hline
\end{tabular}


Haemulon sciurus, the blue-striped grunt, and Holocentrus ascensionis, the squirrelfish, took place in four to five days as contrasted with our 21 day average.

The behavioral basis for this species difference is still unknown, but one possible explanation involves signal discriminability. If the signal being presented in one modality is more intense than the signal presented in the other, the first will be more efficiently discriminated and responded to. Indeed, one objection frequently made to studies of the kind reported here is that the intensity of the signals presented in the two modalities has not been equated. The problem here has been the lack of a measuring system which would permit cross-modal intensity estimation.

One possible way of doing cross-modal measurements of signal discriminability is to use the theory of signal detection developed by Swets and his colleagues (Green \& Swets, 1966). This theory provides a measure of the detectability of any signal which is independent of the physical parameters of the signals, by measuring detectability solely in terms of response probabilities in the presence, as opposed to the absence of, a signal. Signals which produce similar probability of response levels could then be used in studying behavioral and physiological responses to stimuli affecting different receptors.

\section{REFERENCES}

BEHREND, E. R., \& BITTERMAN, M. E. Avoidance-conditioning in the goldfish: Exploratory studies of the CS-US interval. Amer. J. Psychol,
$1962,75,18-34$.

BIEDERMAN, G. B. Discriminated avoidance conditioning: Stimulus function in shaping and training. Psychon. Sci., 1967, 9, 263-264.

CALDWELL, D. K. The biology and systematics of the pinfish, Lagodon rhomboides (Linneaus). Bull Flo. St. Mus, 1957, 2, 78-173.

D'AMATO, M. R., KELLER, D., \& DiCARA, L. Facilitation of discriminated avoidance learning by discontinuous shock. J. comp. physiol Psychol, $1964,58,344-349$.

GREEN, D. M., \& SWETS, J. A. Signal detection theory and psychophysics. New York: Wiley \& Sons, 1966.

JACOBS, D. W., \& TAVOLGA, W. N. Acoustic intensity limens in the goldfish. Anim Behov., 1967, 15, 324-335.

TAVOLGA, W. N. The audio-ichthyotron-the evolution of an instrument for testing the auditory capacities of fishes. Trans. N. Y. Acad. Sci, Ser. II, $1966,28,706-712$.

TAVOLGA, W. N., \& WODINSKY, J. Auditory capacities in fishes. Pure tone thresholds in nine species of marine teleosts. Bull. Amer. Mus. Nat. Hist., $1963,126,179-239$.

\section{NOTE}

1. This project was supported in part by an NSF Grant (GB-4364) and in part by Contract 552(06) with the Office of Naval Research. We are grateful to Dr. William N. Tavolga for his advice and to Mrs. Roberta Scott and Mrs. Brigitte Cappelli for their assistance. This report is a contribution of the Mote Marine Laboratory, Sarasota, Florida (formerly the Cape Haze Marine Laboratory). 